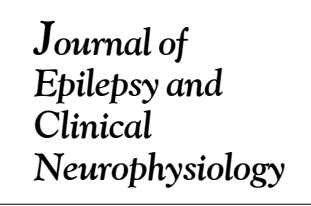

J Epilepsy Clin Neurophysiol 2006; 12 (1):37-40
Editor convidado:

LUCIANO DE PAOLA

\title{
Clinical Features of Psychogenic Nonepileptic Seizures (PNES): Analysis of a Brazilian Series
}

\author{
Luciano De Paola*,**, Carlos Silvado*,**, Maria Joana Mäder*,**, Gisele R. Minhoto*,**, \\ Lineu C. Werneck* \\ Internal Medicine Department, Hospital de Clinicas da Universidade Federal do Paraná, Curitiba, PR
}

\begin{abstract}
Rationale: An estimate of 3 million people present with the diagnosis of epilepsy in Brazil. Psychogenic Nonepileptic Seizures (PNES) are likely to occur in up to 2-33/100.000 people. Paradoxically, very few papers address this significant condition in the Brazilian literature. We describe a Brazilian PNES population and provide a review of the literature. Methods: we reviewed the clinical history, vídeo-electroencephalographic (VEEG) data, psychiatric diagnosis and prognosis in a series of 45 PNES patients, with emphasis on the demographics, as well as, PNES major clinical presentations and classification. Results: PNES represent $5.2 \%$ of the patients referred to the VEEG monitoring at our institution; patients were mostly young with a mean age of $27 \mathrm{y} / \mathrm{o}$ and a clear predominance of the female gender $(78 \%)$; the majority of PNES last between 1-5 minutes, but duration was highly variable; $28 / 45$ patients were referred due to "intractable epilepsy" and 14/28 had MR defined mesial temporal sclerosis; about a third of the patients present with the classically described PNES clinical presentation; conversive and dissociative seizures prevail on PNES classification (80\%). Conclusions: clinical and VEEG data on this Brazilian population matches descriptions coming from other series, suggesting potential cross-cultural similarities in the clinical expression of this condition.
\end{abstract}

Key words: psychogenic nonepileptic seizures, nonepileptic seizures, pseudo-seizures.

\section{RESUMO}

Características clínicas das crises não-epilépticas psicogênicas (CNEP): análise de uma série de pacientes brasileiros

Aproximadamente 3 milhões de pessoas tem o diagnóstico de epilepsia no Brasil e dados atuais sugerem uma prevalência de crises não-epilépticas psicogênicas da ordem de 2-33/100.000 indivíduos. Paradoxalmente, há pouco material publicado sobre o tema na literatura nacional. Estudamos uma população de pacientes brasileiros portadores de CNEP e realizamos uma revisão da literatura. Métodos: a história clinica, resultados da avaliação por video-eletrencefalograma (VEEG), o diagnóstico psiquiátrico e o prognóstico foram avaliados em uma série de 45 pacientes portadores de CNEP, com ênfase em dados demográficos, semiológicos e de classificação. Resultados: CNEP representaram 5.2\% dos pacientes referidos para monitorização com VEEG em nosso serviço. Os pacientes em sua maioria foram jovens, com idade média de 27 anos e clara predominância do sexo feminino (78\%). A maior parte das CNEP durou de 1-5 minutos, mas este dado foi variável. 28 pacientes foram encaminhados em função de "epilepsia intratável" e 14 destes apresentavam esclerose mesial temporal definida por RM. 33\% apresentaram a clássica semiologia relacionada às CNEP. Crises de origem conversiva ou dissociativa foram predominantes na classificação psiquiátrica (80\%). Conclusões: dados clínicos e de VEEG nesta população são superponíveis aos descritos em outras séries, sugerindo similaridades interculturais na expressão clínica das CNEP.

Unitermos: crises não-epilépticas psicogênicas, crises não-epilépticas, pseudocrises.

\footnotetext{
* Epilepsy Program, Neurology, Internal Medicine Department, Hospital de Clinicas da Universidade Federal do Parana, Curitiba, Brazil. ** EPICENTRO - Epilepsy and Sleep Disorders Centre, Hospital XV, Curitiba, Paraná, Brazil.

Received Jan. 25, 2006; accepted Fev. 24, 2006.
} 
Benbadis and Hauser ${ }^{(1)}$ have recently published an estimate based on calculation of the prevalence of pyschogenic nonepileptic seizures (PNES). They took in consideration well known estimates, such as the prevalence of epilepsy $(0.5-1 \%)$, proportion of intractable epilepsy (20-30\%), referrals to tertiary epilepsy centres (20-50\%) and a percentage of patients on such centres who are diagnosed with PNES (10-20\%). They concluded that the prevalence of PNES is somewhere between 2-33 per 100.000. In that case, among the 170 million inhabitants in Brazil, close to 60.000 people might present with PNES.

Regretfully, there is very little written in the Brazilian literature pertaining to PNES seizures. One distinct exception would be the papers by Gomes et al. ${ }^{(2,3)}$ which is essentially represent a prevalence study, based on a twophase design. First a community survey was conducted aiming to identify patients suspect of having epilepsy; the second phase consisted of an interview using a questionnaire adapted from a somewhat similar populational study which took place in the highlands of Northern Ecuador ${ }^{(4)}$. Subjects who tested positive according to the questionnaire were then subjected to a non-structured neurological interview in which suspected nonepileptic seizures (NES) were identified. The diagnosis of syncope prevails among the physiologic NES (35\%). Dissociative and anxiety disorders were the most frequent DSM-IV based diagnosis for the psychogenic PNES sample. However, video-EEG documentation was not available in these series, preventing detailed analysis of the events in dispute.

We recently published data on a National survey among eight epilepsy centres in Brazil ${ }^{(5)}$, which, as a group evaluate close to 20.000 patients per year, of whom over 1300 (per year) are admitted for VEEG monitoring. About 100 patients are diagnosed with PNES on a year basis, a disproportionately low figure, probably representing a referral bias towards surgical cases. Nonetheless, it suggests a lack of diagnosis of PNES. In addition, our survey disclosed optimistic percentages of remission (close to $70 \%$ ), which, in fact, has been described ${ }^{(6,7)}$. A fair amount of papers, however, suggest that good outcomes are observed in no more than $50 \%$ of patients ${ }^{(8,9,10)}$.

Since a disease may vary its clinical expression according to different cultures and social and professional consequences of a given medical diagnosis are also intrinsically related to cultural aspects, we describe a Brazilian series of patients and compared it to the traditionally published PNES data.

\section{MATERIAL AND METHODS}

We retrospectively studied all VEEG documented cases of PNES at our institution. Charts were reviewed and data were collected for demographics, VEEG indication, suspected diagnosis prior to the referral, drug treatment regime, PNES clinical presentation and classification and PNES outcome, when available. The profile obtained was compared to the literature.

\section{RESULTS}

Between 1996 and July, 2003, 1258 patients performed prolonged VEEG recordings at our institutions and of these, 65 (5.2\%) were diagnosed with PNES. In 45/65 patients the chart information was considered complete and consistent to be analysed.

There were 10 male and 35 (78\%) female patients, with a mean age of $27.4 \mathrm{y} / \mathrm{o}$ (range $4-58 \mathrm{y} / \mathrm{o}$ ). A mean of $3.3(1-14)$ events were recorded per patient. In 15 (33\%) patients the NES duration was less than a minute, in $21(47 \%)$ last between 1 and 5 minutes, in $8(18 \%)$ the duration was between 5 and 25 minutes and 1 patient presented with a NES lasting over an hour.

There were three main reasons for referral. Twentyeight (62\%) patients were thought to present with "refractory epilepsy" and were referred for seizure documentation aiming to drug adjustment and/or epilepsy surgery; in this group all patients were on antiepileptic drugs (AEDs) and a mean of 58 (2-216 hr) of VEEG recording was obtained per patient. Fourteen patients had magnetic resonance (MR) proven mesial temporal sclerosis (MTS). Of these 10/14 were referred for surgical evaluation and 4/14 had been already subjected to temporal lobectomies, none of whom had presented with NES prior to his/her surgery.

Ten patients (22\%) consisted of a "mixed seizure group", referred under the suspicion of coexistence of epilepsy and PNES; in this group patients were all on AEDs and a mean of $58(17-120 \mathrm{hr})$ of VEEG recording was obtained per patient.

Seven (16\%) patients were referred with a high suspicion of "pure NES"; in this group none were taking AEDs and a mean of 24(4-72 hr) of VEEG were recorded per patient.

Fifteen $(33 \%)$ of all patients presented with the socalled "classic" clinical expressions of NES, including sideto-side head movement, pelvic movements, out-of-phase limb movements and opisthotonus. The more common combination was the side-to-side head movement along with out-of-phase limb movement in 11/15 patients. Eight patients presented with the full spectrum, including head, pelvic, limb movements and opisthotonus. Curiously, this subgroup included $5 / 8$ patients with refractory epilepsy and MR proven mesial temporal sclerosis (MTS).

In this series of 45 patients there was no evidence of incontinence and a clear cut history of sexual abuse was not given by any of the patients. 
An attempt of classification using the DSM-IV was carried out, but proved to be possible in only $34 / 45$ (75\%) of the patients, in whom the clinical interview produced more consistent psychiatric semiology. Seventeen (50\%) of the patients were defined as having conversion seizures, $11(32 \%)$ as dissociative seizures, $3(9 \%)$ as factitious disorder, $2(6 \%)$ as malingering and 1 patient received the diagnosis of conversion-dissociative seizures.

Only 10/34(29\%) patients classified according to the DSM-IV were followed closely with either psychiatric or psychological consults for at least one year. Only three (30\%) showed significant improvement, without complete remission of symptoms.

\section{DISCUSSION}

The low incidence of PNES cases in our population is noticeable when compared to the usually referred 10-20\% in the same setting ${ }^{(11)}$. At least part of the explanation may be related to a selection bias, since admissions tend to be highly selective towards potentially surgical cases, preferably the ones with imaging defined structural lesions. Admissions aiming specifically to differential diagnosis do not represent a priority indication in our setting.

The marked predominance of young female patients in our series is consistent with figures commonly reported for both adult and pediatric/adolescent populations ${ }^{(8,9,12,13)}$.

Fourteen patients in our series were diagnosed with mesial temporal lobe epilepsy related to MTS. Four patients had been previously subjected to temporal lobectomies and presented with PNES afterwards. They represent $3.4 \%$ of our own series of 118 temporal lobectomy (related to MTS) cases, which is consistent with the 3.5 to $4.6 \%$ incidence, reported in other series ${ }^{(14,15)}$ and a little below the $8 \%$ reported by Henry and Drury ${ }^{(16)}$. Glosser et al.(17) described a "disproportionate number of postsurgical PNES patients as female, with a primary neuro-dysfunction on the right hemisphere". This is in fact the case of our four subjects, an interesting but, yet probably just coincidental situation. The gender predominance mentioned on Glosser's observation, as already discussed, comes as no surprise in any given PNES population. The existence of PNES in patients with known MTS has been already described ${ }^{(18)}$. The unknown data, however, is how many of such patients have "pure" PNES, meaning no diagnosis of epilepsy, in spite of their MR proven structural abnormality. Moore et al. ${ }^{(19)}$ recently have reported on only "two false positives" (i.e., patients with MTS and no seizures) of 207 patients who had an MR for hearing loss and had no history of seizures. On the other hand, the existence of an "abnormality" in a given imaging study may indeed compromise the diagnosis of PNES for patients and relatives. This potentially confusing scenario only emphasizes on the need of seizure documentation on MTS patients, as opposed to bypassing this part of the protocol and leading them straight to surgery, a controversial and highly debatable issue.

Gates et al. ${ }^{(20)}$ described what could be defined as "classic" PNES clinical expressions. More recently, Gates ${ }^{(21)}$ advised "humility on the part of the epileptologist and clinical neurophysiologist", as frontal lobe onset complex partial seizures may clearly resemble PNES. Keeping the caveat in mind, "classic" PNES clinical expressions include side-to-side head movements, pelvic thrusting, opisthotonus and out-of-phase limb movements. More striking, however, was the observation that of the 8 patients in whom all signs were present, 5 had MRI evidence of MTS and were referred for epilepsy surgery. Numbers are small but, one would imagine that with their knowledge of epilepsy, frequent hospitalizations and familiarity with other people with epilepsy these patients would display a more "seizure-like" behaviour, as opposed to the flourished presentation observed. Certain features of this subset of patients resemble the so-called "highlighters" described by Gates et al.(22) on previous reports. According to Gates, these patients have to "selffulfil prophecy of secondary generalization" or, in other words, simple or complex partial seizures as a rule do not call as much attention as "generalized" events.

Urinary incontinence has been reported in PNES and Lancman et al. ${ }^{(23)}$ discussed this issue concluding that this feature may account for a "delayed" incorporation in the PNES description, since they do not identify it in early stages of the presentation. We have not documented incontinence during any of the events reported in our series, but the subgroup of mixed epileptic-PNES (in particular the ones prone to secondary generalization) did refer to this occurrence. Lancman also pointed out that the duration of PNES is not a reliable discriminator between epileptic and PNES, a fact that matches with our observation on the extreme variation on duration of the PNES.

On a similar line, we have not seen a clear cut history of sexual abuse in this series. This specific issue has been already discussed and the association of sexual abuse and PNES appears to be fairly common ${ }^{(24)}$. Figures in the general population are already impressive as nearly $25 \%$ of women report that they have been raped and/or physically assaulted by a current partner, former spouse, cohabiting partner or date at some time in their life. Specifically, about $15 \%$ of adult incest victims report PNES or other distinct somatic symptoms. In that sense, a major criticism in our series would be the lack of a structured interview aiming to unfold that diagnosis, which may account for the apparent absence of these events.

We tried to accommodate our patients within the socalled "alternative classification", based on the DSM-IV and proposed by Martin and Gates ${ }^{25)}$. We were not able classify to all patients in the series, since data were not 
considered consistent enough in 11 patients. The remaining patients clustered on both the conversion and dissociative seizure groups, with the predominance of the former, just like it was previously described by Gates and Mercer $^{(6)}$.

PNES outcome was assessed on only 10 patients in the present series, with the minority achieving resolution or prolonged remission of their PNES. The other patients were either re-directed to the referral physician (as they were originally referred exclusively for diagnosis) or quite simply lost follow up. Unfortunately numbers are too protracted to extrapolate these results as to define clinical features that ultimately lead to a better prognosis. This figure, however, is lower than reported by most centres. Explanation for the inconsistency is likely to be two fold: lack of personnel (such as a dedicated psychologist and/or psychiatrist) and the unfavourable social aspects inherent to the population studied, jeopardizing scheduling and compliance to treatment.

Finally, considering the whole group of patients, we felt patients could be classified in four groups, based on the predominant clinical features of their PNES. Thus, the "predominantly motor expression" group (including tremor, posturing, tonic/tonic-clonic/myoclonic-like seizures and random movements) represents the largest group, with $25(56 \%)$ cases. The "intense discomfort" group (including dizziness, palpitations and hyperventilation) was the second largest group with $14(31 \%)$ patients. Smaller groups were defined as "hypotonia and unresponsiveness" group in $4(9 \%)$ patients and the "sensory localised symptoms" group, with 2 (4\%) patients, defined as tingling and numbness sensations over a specific body segment. These four broader groups have a practical appeal to it, as they indeed encompass the majority of patients. However, it would take a larger sample to validate this effort as an alternative PNES classification.

\section{CONCLUSIONS}

PNES represent a common and yet, challenging diagnosis. Our data suggest that PNES are likely to be underdiagnosed, in spite of their relatively flourished clinical expression. The clinical aspects observed in our series resemble currently published literature, suggesting cross-cultural similarities in the clinical expression of PNES.

\section{REFERENCES}

1. Benbadis SR, Hauser WA. An estimate of the prevalence of psychogenic non-epileptic seizures. Seizure 2000; 9:280-1.

2. Gomes MM, Kropf LAL, van Beeck ES, Figueira ILV. Inferences from a community study about non-epileptic events. Arq NeuroPsiquiatr 2002; 60:712-6.

3. Gomes MM, Zeitoune RG, Kropf LAL, van Beeck ES. A house-tohouse survey of epileptic seizures in a urban community of Rio de Janeiro-Brazil. Arq Neuro-Psiquiatr 2002; 60:708-11.
4. Placencia M, Suarez J, Crespo F et al. A large-scale study of epilepsy in Ecuardor: methodological aspects. Neuroepidemiology 1992; 11:74-84.

5. De Paola L, Pamini AL, Yacubian EM et al. Nonepileptic seizures (NES) in Brazil: Results on a national survey. J Epilepsy Clin Neurophysiol 2004; 10:109-12.

6. Gates JR, Mercer K. Nonepileptic events. Seminars in Neurology $1995 ; 2: 167-74$.

7. Abouskasm A, Mahr G, Gahry BR, Thomas A, Barkley G. Retrospective analysis of the effects of psychotherapeutic interventions on outcomes of psychogenic nonepileptic seizures. Epilepsia 1998; 39:470-3.

8. Ettinger AB, Devinsky O, Weisbrot DM, Ramakrishna RK, Goyal A. A comprehensive profile of clinical, psychiatric, and psychosocial characteristics of patients with psychogenic nonepileptic seizures. Epilepsia 1999; 40:1292-8.

9. Selwa LM, Geyer J, Nikakhtar N, Brown MB, Schuh LA, Drury I. Nonepileptic seizure outcome varies by type of spell and duration of illness. Epilepsia 2000; 41:1330-4.

10. Silva W, Giagante B, Saizar R et al. Clinical features and prognosis of nonepileptic seizures in a developing country. Epilepsia 2001; 42:398-401.

11. Gates JR. Epidemiology and classification of non-epileptic events. In: Gates JR, Rowan AJ, editors. Non-epileptic seizures. $2^{\text {nd }}$ ed. Boston: Butterworth-Heinemann; 2000. p. 3-14.

12. Szaflarski JP, Ficker DM, Cahill WT, Privitera MD. Four-year incidence of psychogenic nonepileptic seizures in adults in Hamilton County, OH. Neurology 2000; 10:1561-3.

13. Wyllie E, Glazer JP, Benbadis S, Kotagal P, Wolgamuth B. Psychiatric features of children and adolescents with pseudoseizures. Arch Pediatr Adolesc Med 1999; 153:244-8.

14. Davies KG, Blumer DP, Lobo S, Hermann BP, Phillips BL, Montouris GD. De novo nonepileptic seizures after cranial surgery of epilepsy: Incidence and risk factors. Epilepsy Behav 2000; 1:436-3.

15. Reuber M, Kral T, Kurthen M, Elger CE. New-onset psychogenic seizures after intracranial neurosurgery. Acta Neurochir 2002; 144:901-7.

16. Henry TR, Drury I. Non-epileptic seizures in temporal lobectomy candidates with medically refractory seizures. Neurology 1997; 48:1374-82.

17. Glosser G, Roberts D, Glosser DS. Nonepileptic seizures after resective epilepsy surgery. Epilepsia 1999; 40:1750-4.

18. Benbadis SR, Tantum WO, Murtagh R, Vale FL. MRI Evidence of mesial temporal sclerosis in patients with psychogenic nonepileptic seizures. Neurology 2000; 55:1061-2.

19. Moore KR, Swallow CE, Tsuruda JS. Incidental detection of hippocampal sclerosis on MR images: is it significant? Am J Neuroradiol 1999; 20:1609-12.

20. Gates JR, Ramani V, Whalen S, Loewenson R. Ictal characteristics of pseudoseizures. Arch Neurol 1985; 42:1183-7.

21. Gates JR. Nonepileptic seizures: time for progress. Epilepsy \& Behavior 2000; 1:2-6.

22. Gates JR, Erdahl P. Classification of non-epileptic events. In: Rowan AJ, Gates JR, editors. Non-epileptic seizures. $1^{\text {st }}$ ed. Boston: Butterworth-Heinemann; 1993. p. 21-30.

23. Lancman ME, Lambrakis CC, Steinhardt MI. Psychogenic pseudoseizures. In: Ettinger AE, Kanner AM, editors. Psychiatric issues in epilepsy: A practical guide do diagnosis and treatment. Philadelphia: Lippincott Williams \& Wilkins; 2001. p. 341-57.

24. De Paola L. What is the association between sexual abuse and nonepileptic seizures? Epilepsia 2001; 42 (suppl 2):6-7.

25. Martin RL, Gates JR. Nosology, classification, and differential diagnosis of non-epileptic seizures: An alternative proposal. In: Gates JR, Rowan AJ, editors. Non-epileptic seizures. $2^{\text {nd }}$ ed. Boston: Butterworth-Heinemann; 2000. p. 253-76.

Address for correspondence:

Luciano De Paola

Hospital de Clínicas Epilepsy Program

Rua General Carneiro, 181 - 3ㅇandar

CEP 80060-900, Curitiba, PR, Brazil

E-mail:1lpaola@mps.com.br 